\title{
Decomposição dos índices de desenvolvimento humano e social da Microrregião de Foz do Iguaçu: uma aplicação da análise shift-
} share para 1991 e $2000^{89}$

\author{
Decomposition of human and social development indexes of the Micro Region of Foz \\ do Iguaçu: an application of shift-share analysis for 1991 and 2000
}

Diego Camargo Botassio $0^{90}$

Artigo recebido para publicação em Ago/2013 e aceito para publicação em Ago/2013.

\begin{abstract}
RESUMO
O presente trabalho busca fazer uma análise do crescimento dos índices de desenvolvimento humano e social na Microrregião de Foz do Iguaçu, utilizando a técnica de análise regional shift-share (estrutural-diferencial) nos indicadores de 1991 e 2000. Para tal, utilizou-se indicadores básicos de desenvolvimento humano publicados pelo Programa das Nações Unidas para o Desenvolvimento. Ao fim, se obtêm quais cidades da microrregião obtiveram maiores variações de cada índice, assim como as que não tiveram resultados tão expressivos. Porém, para o período todos municípios apresentaram crescimento em seus índices e indicadores de desenvolvimento (a exceção do coeficiente de Gini). $O$ estudo demonstrou que a aplicação da metodologia é de grande utilidade para a detecção de indicadores de desenvolvimento humano e social que desempenharam melhor papel para o avanço do desenvolvimento em cada município comparando-o com a região, além de identificar em cada caso onde há problemas de eficiência alocativa, assim como ativação social.
\end{abstract}

Palavras-Chave: Microrregião de Foz do Iguaçu. Shift-share. Desenvolvimento Humano.

\begin{abstract}
This paper aims to analyze the variation of the human development index in the Micro Region of Foz do lguaçu, using the technique of regional shift-share analysis (structural-differential) for 1991 and 2000. For this, we used basic indicators of human development published by United Nations Development Program. At the end, which is obtained from the cities had higher variations of each index, as well as those who did not results so expressive. But for the period all municipalities had positive changes in their indexes and indicators of development (except the Gini coefficient). Finally, the study demonstrated that the application of the methodology is useful for the detection of human and social development indicators role they play better to advance development in each city by comparing with the region, and to identify in each case where there are problems of allocative efficiency, and social activation.
\end{abstract}

Keywords: Micro Region of Foz do Iguaçu. Shift-share. Human Development.

\footnotetext{
${ }^{89}$ Pesquisa desenvolvida no Projeto Construção da Matriz Informacional HINCO da Microrregião de Foz do Iguaçu: identificação de entraves e potencialidades para o desenvolvimento regional sob a coordenação do prof. Dr. Gilson Batista de Oliveira.

${ }^{90}$ Bolsista do PROBIC/UNILA - Universidade Federal da Integração Latino-Americana. E-mail: diego.botassio@unila.edu.br

${ }^{91}$ Doutor em Desenvolvimento Econômico pela Universidade Federal do Paraná. Professor Adjunto II da Universidade Federal da Integração Latino-Americana. E-mail: gilson.oliveira@unila.edu.br
} 


\section{INTRODUÇÃO}

A análise regional tem importante papel quanto há problemas pontuais a serem diagnosticados, tanto para economistas, quanto para os geógrafos e ou demais cientistas sociais. De acordo com Azzoni (2003, p.1), há dois modos de caracterizar a existência "de um 'problema regional': desigualdade e concentração". Quando se têm tais temas, vem a mente a distribuição de riqueza e renda que é ponto fundante do desenvolvimento econômico. Mais do que isso, se necessita, além de altos recursos e sua distribuição, que a sociedade se veja em boas situações de vida.

O presente trabalho busca fazer uma análise do crescimento dos índices de desenvolvimento humano e social na Microrregião de Foz do Iguaçu (MFI), utilizando a técnica de análise regional shift-share (estrutural-diferencial) nos indicadores que compõem os referidos índices para os anos de 1991 e 2000.

O município mais antigo da MFI é o mesmo que lhe dá nome. O município de Foz do Iguaçu foi fundado em 1914, originado de uma antiga Colônia Militar existente na região desde 1989 (PIERUCCINI, TSCHÁ, e IWAKE, 2008). Desde sua fundação, a região foi palco de diversos processos de emancipação de municípios e recortes geográficos que, em 1990, levou a criação da microrregião.

\section{A MICRORREGIÃO DE FOZ DO IGUAÇU}

A Microrregião de Foz do Iguaçu (MFI), hoje constituída por 11 municípios, foi criada a partir da divisão regional geográfica estabelecida pelo Instituto Brasileiro de Geografia e Estatística (IBGE) no ano de 1990 (IBGE, 1990). As microrregiões geográficas são espaços derivados de territórios maiores denominados mesorregiões $^{92}$ e estas são definidas por um conceito mais abrangente de identidade regional, por determinação de regiões mais tradicionais levando em consideração os centros urbanos de grande importância local e sua posição

\footnotetext{
92 Anterior à publicação do IBGE não havia a segregação em mesorregiões, somente existindo a divisão regional em "microrregiões homogêneas" (IBGE, 1990). Detalhes sobre a divisão regional do Paraná antes do período estudado ver Muniz Filho (1996).
} 
geográfica. Por outro lado, as microrregiões são definidas, inicialmente, por um aporte tradicional nomeado pelo município mais antigo ou que represente maior articulação no espaço geográfico e aporte de hierarquia urbana levando em consideração, de acordo com Raiher (2009, p. 19), as características "referentes à estrutura de produção agropecuária, industrial, de extrativismo mineral, ou de pesca" e as relações de troca, distribuição e consumo entre as cidades que compõem a microrregião.

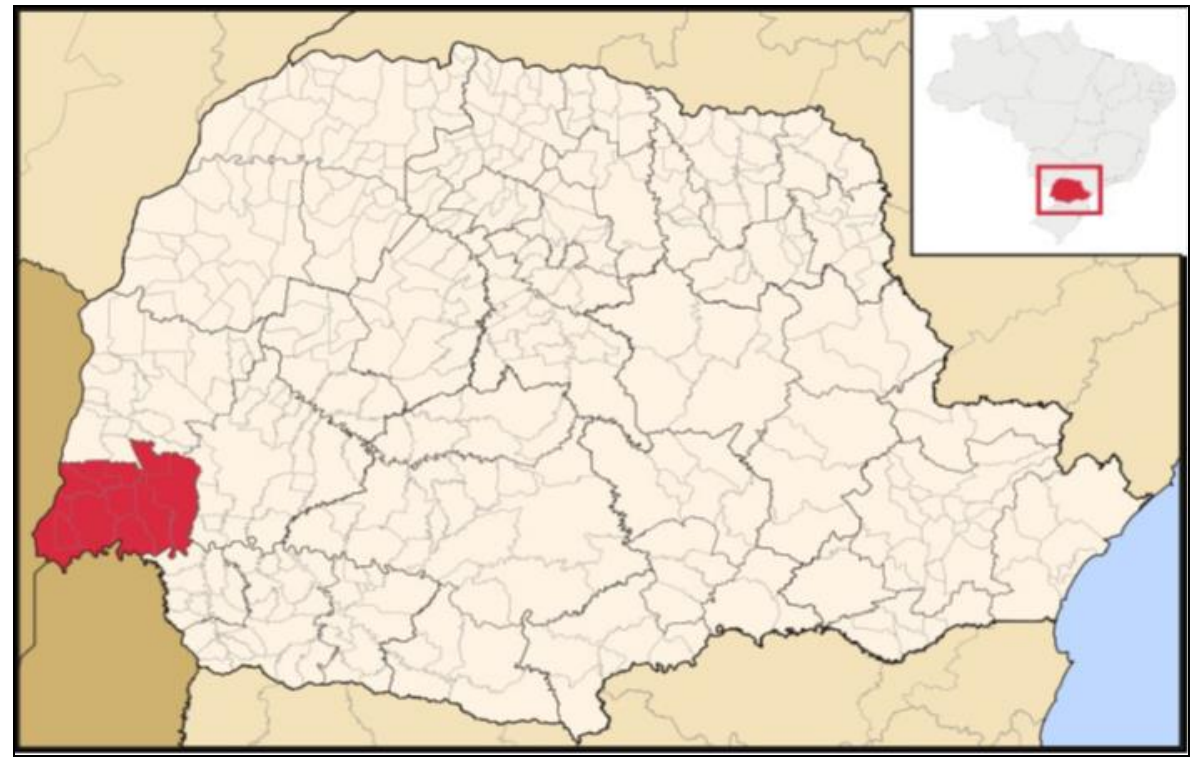

Figura 1. Localização geográfica da Microrregião de Foz do Iguaçu Fonte: IBGE, 2012.

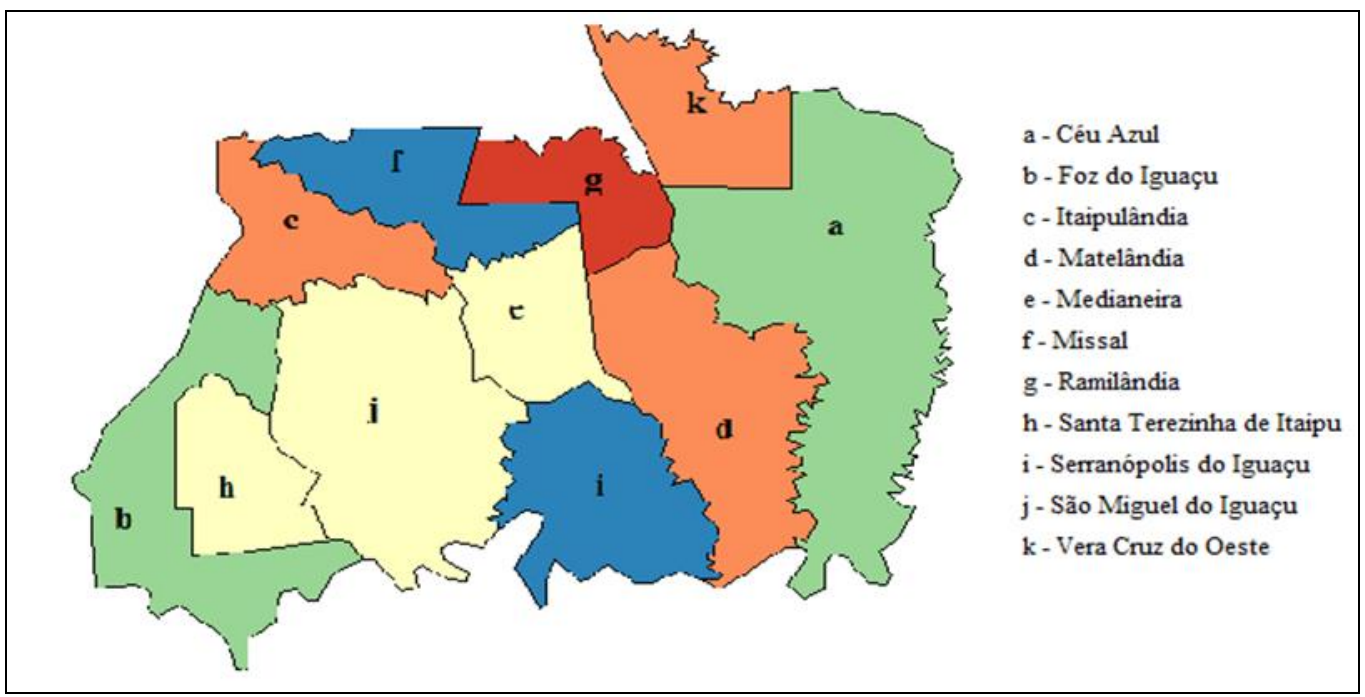

Figura 2. Municípios da Microrregião de Foz do Iguaçu.

Fonte: Atlas do Desenvolvimento Humano (PNUD, 2003) 
Na publicação do IBGE (1990) a MFI era constituída por oito municípios. Porém, durante a década de 1990 houve processos de emancipação de três municípios que foram incorporados à microrregião. Os municípios incorporados foram Ramilândia (1991), Itaipulândia (1992) e Serranópolis do Iguaçu (1995). Assim, de acordo com o Atlas do Desenvolvimento Humano no Brasil (PNUD, 2003) a MFI é, assim como segue nos dias atuais, constituída pelos municípios Céu Azul, Foz do Iguaçu, Itaipulândia, Matelândia, Medianeira, Missal, Ramilândia, Santa Terezinha do Itaipu, São Miguel do Iguaçu, Serranópolis do Iguaçu e Vera Cruz do Oeste, localizada dentro da mesorregião do oeste paranaense - mapas 01 e 02.

A região de análise se localiza no extremo oeste paranaense abarcando uma área total de 5.588,2 km², altitude variável entre 164 (Foz do Iguaçu) e 620 metros (Céu Azul) e população de 399.487 habitantes para o fim do período analisado. O município que dá nome a microrregião está a $533 \mathrm{~km}$ da capital do estado, Curitiba, sendo dos 11 municípios o mais distante. A densidade demográfica da região é de $71,5 \mathrm{hab} . / \mathrm{km}^{2}$, porém existe uma grande disparidade analisando município a município. De acordo com Rolim (2004, p.4), Foz do Iguaçu possui "um dos mais elevados graus de urbanização do Brasil: 99,22\%". Enquanto isso, os municípios de Serranópolis do Iguaçu (40,68\%), Ramilândia (45,35\%) e Missal $(47,66 \%)$ apresentam as menores concentrações populacionais.

Tabela 01: dados referentes a população e urbanização na MFI: 2000

\begin{tabular}{lrrrrr}
\hline \multicolumn{1}{c}{ Municipio } & Pop. total & Pop. rural & \multicolumn{1}{c}{ Pop. } & hab/ $\mathrm{Km}^{2}$ & Urbanização \\
\hline Céu Azul & 10.445 & 3.248 & 7.197 & 8,8 & $68,90 \%$ \\
Foz do Iguaçu & 258.543 & 2.019 & 256.524 & 437,7 & $99,22 \%$ \\
Itaipulândia & 6.836 & 3.079 & 3.757 & 20,2 & $54,96 \%$ \\
Matelândia & 14.344 & 4.193 & 10.151 & 22,0 & $70,77 \%$ \\
Medianeira & 37.827 & 4.581 & 33.246 & 127,9 & $87,89 \%$ \\
Missal & 10.433 & 5.461 & 4.972 & 30,1 & $47,66 \%$ \\
Ramilândia & 3.868 & 2.114 & 1.754 & 15,7 & $45,35 \%$ \\
Santa Terezinha de Itaipu & 18.368 & 2.069 & 16.299 & 63,5 & $88,74 \%$ \\
Serranópolis do Iguaçu & 4.740 & 2.812 & 1.928 & 9,8 & $40,68 \%$ \\
São Miguel do Iguaçu & 24.432 & 10.172 & 14.260 & 28,5 & $58,37 \%$ \\
Vera Cruz do Oeste & 9.651 & 2.685 & 6.966 & 30,9 & $72,18 \%$ \\
Fonte: PNUD, 2003. & & & & &
\end{tabular}

A respeito do crescimento demográfico, desde 1980, a MFI se destaca no contexto estadual.

"É importante destacar a emergência da microrregião de Foz do Iguaçu a partir dos anos de 1980, como concentradora de população urbana no contexto estadual. Todos os municípios que formam esta microrregião 
apresentaram evolução significativa do número de população urbana no período de 1970 a 2000". (IBGE ${ }^{93}, 2005$ apud ALVES, 2005)

Alves (2005) explica que tal crescimento demográfico ocorre por dois motivos: primeiro, resultado da grande demanda de trabalhadores para a construção da Usina Hidrelétrica de Itaipu e segundo a posição geográfica da microrregião, pois faz fronteira com Paraguai e Argentina.

Quanto às atividades econômicas na microrregião, Lima (2007) cita diversas características regionais. Para esse autor a MFI não apresenta nenhuma dispersão quanto às atividades dos ramos da indústria mais dinâmicas, como metalúrgica e indústria do papel. Por outro lado, a indústria de calçados, produtos alimentícios e extração mineral aparecem de forma significativa. Obteve-se também destaque para a indústria de produtos minerais não metálicos e construção civil, que, como salienta o autor, são "indústrias não tradicionais das microrregiões paranaenses"94. O setor terciário, assim como o comércio, tem papel expressivo na região. Já o setor primário, setor mais disperso no Paraná, vem perdendo localização significativa nesta região desde 1985 .

\section{CONCEITO DE DESENVOLVIMENTO}

O conceito de desenvolvimento, em especial desenvolvimento econômico, muitas vezes se confunde com outro conceito econômico, o do crescimento. Crescimento deve ser entendido como aumento real no nível de renda, isto é, incrementos positivos no PIB - Produto Interno Bruto. Estes incrementos podem ser alcançados por meio de um processo de industrialização ou outras políticas. Tal conceito não abarca necessariamente o conceito de desenvolvimento, que é mais amplo. Desenvolvimento econômico entende-se pela melhor distribuição da renda e da riqueza em uma sociedade, ou seja, quanto mais distribuída for a renda e a riqueza mais desenvolvida será a sociedade. (SANDRONI, 1999; OLIVEIRA, 2002 e 2010).

\footnotetext{
${ }^{93}$ IBGE. Banco de dados agregados - SIDRA. Disponível em: <http://www.sidra.ibge.gov.br/bda/>. 2005.

${ }^{94}$ Ibid., p. 12.
} 
A discussão do conceito de desenvolvimento ganha força no período póssegunda guerra mundial, contudo, o termo desenvolvimento é utilizado para pregar uma noção de progresso econômico. Porém, o debate acerca do quê é desenvolvimento possui suas diversas vertentes, tanto acadêmicas quanto políticoideológico (discurso político). Um exemplo disso está nas interpretações das escolas de pensamento econômico. Comparando a visão do autor estadunidense Walt Whitman Rostow (1916-2003) e o pensamento latino-americano, criado a partir dos pensadores da Comissão Econômica para América Latina e Caribe (CEPAL), fica evidente as divergências de interpretação. Rostow vê o desenvolvimento como algo a ser alcançado - etapista - enquanto o pensamento cepalino, em especial o de Celso Furtado, encara o desenvolvimento como uma consequência do subdesenvolvimento, com condições impostas do centro a periferia, não percorrendo um caminho em etapas.

A noção de desenvolvimento que se considera neste trabalho abarca não só a renda (termo econômico), mas também a qualidade de vida da população, levando em consideração também sua educação e saúde, caracterizando não somente o desenvolvimento como econômico, mas também humano e social, pois "o que importa, na verdade, mais do que o simples nível de crescimento ou de industrialização, é como os frutos do progresso, da industrialização, do crescimento econômico são distribuídos para a população, de modo a melhorar a vida de todos" (OLIVEIRA, 2002, p.45).

Para a análise de desenvolvimento que se leva a cabo utiliza-se os indicadores de renda, educação e saúde. Os dados brutos utilizados nessa pesquisa são obtidos no Atlas do Desenvolvimento Humano (PNUD, 2003):

PIB per capita municipal: é calculado a partir do produto municipal dividido por sua população e adaptado a paridade do poder de compra medido em salários mínimos;

Educação: calculado a partir da Taxa Bruta de Frequência Combinada que utiliza a quantidade de pessoas que frequentam os cursos nos três níveis divididos pela quantidade total de pessoas na faixa etária de 7 a 22 anos (peso 1/3) e taxa de alfabetização (peso 2/3); 
Saúde ou Longevidade: traz a expectativa de vida ao nascer (em anos), com peso de $2 / 3$, e a taxa de mortalidade infantil a cada mil nascidos vivos, com peso de $1 / 3$;

Coeficiente de Gini: indicador utilizado para medir a distribuição da renda em cada município ${ }^{95}$.

Cada um dos indicadores apresenta resultados em uma escala de 0 a 1 (método distancial), sendo 0 (zero) a pior situação para cada indicador e 1 (um) a situação inversa ${ }^{96}$, salvo o Coeficiente de Gini, que precisa de uma adaptação para inverter a interpretação dos resultados.

Os dados brutos retirados do PNUD (2003), expostos na tabela 02, permitiram os cálculos dos índices e indicadores necessários para análise. Optou-se pelos anos bases 1991 e 2000, pois foram anos censitários.

Tabela 02: Da dos brutos da Microrregião de Foz do Iguaçu: 1991 e 2000

\begin{tabular}{|c|c|c|c|c|c|c|c|c|}
\hline Municipio & $\begin{array}{c}\text { Indicador } \\
\text { Educação, } \\
1991\end{array}$ & $\begin{array}{c}\text { Indicador } \\
\text { Educação, } \\
2000\end{array}$ & $\begin{array}{c}\text { Indicador } \\
\text { Longevidad } \\
\text { e, } 1991\end{array}$ & $\begin{array}{c}\text { Indicador } \\
\text { Longevidade, } \\
2000\end{array}$ & $\begin{array}{c}\text { Indicador } \\
\text { Renda, } \\
1991\end{array}$ & $\begin{array}{l}\text { Indicado } \\
\text { rRenda, } \\
2000\end{array}$ & $\begin{array}{c}\text { Indice de } \\
\text { Gini, } \\
1991\end{array}$ & $\begin{array}{l}\text { Indice de } \\
\text { Gini, } 2000\end{array}$ \\
\hline Céu Azul & 0,775 & 0,89 & 0,607 & 0,752 & 0,631 & 0,699 & 0,55 & 0,55 \\
\hline Foz do lg uaçu & 0,801 & 0,905 & 0,647 & 0,721 & 0,719 & 0,739 & 0,58 & 0,58 \\
\hline Ita1pulandia & $0, / 52$ & 0,818 & 0,113 & $0, / 21$ & 0,608 & 0,68 & 0,49 & 0,58 \\
\hline Matelândia & 0,773 & 0,875 & 0,654 & 0,721 & 0,611 & 0,683 & 0,55 & 0,53 \\
\hline Nedianelra & 0,811 & 0,904 & 0,108 & $0, / 21$ & $0,6 / 2$ & 0,112 & 0,21 & 0,01 \\
\hline Missal & 0,817 & 0,898 & 0,713 & 0,786 & 0,637 & 0,686 & 0,61 & 0,55 \\
\hline Ramilandia & 0,666 & $0, / 81$ & 0,11 & $0, / 37$ & 0,544 & $0,5 / 3$ & 0,54 & 0,54 \\
\hline Santa Terezinha de Itaipu & 0,775 & 0,879 & 0,643 & 0,751 & 0,65 & 0,704 & 0,56 & 0,56 \\
\hline Serranópolis do Iguaçu & 0,822 & 0,902 & 0,736 & 0,792 & 0,643 & 0,694 & 0,56 & 0,56 \\
\hline Săo Miguel do Ig uaçu & 0,788 & 0,884 & 0,657 & 0,725 & 0,658 & 0,729 & 0,56 & 0,66 \\
\hline Vera Cruz do Oeste & 0,733 & 0,844 & 0,659 & 0,714 & 0,607 & 0,653 & 0,6 & 0,61 \\
\hline
\end{tabular}

De acordo com PNUD (2003), os valores do Índice de Desenvolvimento Humano (IDH), permitem classificar as cidades em três grupos:

Valores menores que 0,5 : baixo desenvolvimento;

Valores entre 0,5 e 0,8: médio desenvolvimento;

Valores acima de 0,8: alto desenvolvimento.

\footnotetext{
${ }^{95} \mathrm{O}$ Coeficiente de Gini não é o único indicador existente para o cálculo da concentração de renda, porém se optou por utilizá-lo já que é o mais conhecido. O software do PNUD também disponibiliza os dados do Índice $L$ de Theil, um outro coeficiente que mede desigualdade, porém com critérios de cálculo distintos e consequentemente se obtêm outros valores.

${ }^{96}$ Esta metodologia também é denominada de genebrino, onde se utiliza os extremos de máximo e mínimo como referência, sendo 0 extremo inferior e 1 o extremo superior. Os valores intermediários são ponderados conforme este padrão.
} 
Assim, assumindo a mesma segregação dos países quanto seus valores do IDH para municípios, todos os municípios da região em análise, ao fim do período, encontram-se na faixa de municípios com médio desenvolvimento tomando como base o IDH-M. Ademais de isso, sete dos 11 municípios estão entre os $70 \mathrm{com}$ melhor desempenho do IDH-M no Estado do Paraná, um grupo composto pelos 17\% municípios com melhores índices no estado.

Nesse artigo, conforme anteriormente definido, são usados três índices de desenvolvimento humano e social:

1. Índice de Desenvolvimento Humano Municipal (IDH-M) - O Índice de Desenvolvimento Humano (IDH) foi apresentado pela primeira vez no Relatório de Desenvolvimento Humano publicado pela ONU em 1990, que desde então tem uma publicação anual e é, até os dias atuais, o índice de desenvolvimento mais usado para se referir a qualidade de vida da sociedade. Em 1998, três instituições de pesquisa brasileiras ${ }^{97}$, com base no IDH, adaptaram a metodologia para os municípios, criando assim o Índice de Desenvolvimento Humano Municipal (IDH-M). Por se tratar de uma adaptação do índice original (IDH), não se deve fazer comparações dos resultados do IDH com os do IDH-M, pois se tratam de tipos de delimitações geográficas distintas, assim como as aproximações de cálculo;

2. Índice de Desenvolvimento Social (IDS) - Para compensar um erro metodológico proposto no IDH-M, pois a renda per capita não é compatível com o conceito de desenvolvimento quanto a distribuição mais igualitária da renda, o Índice de Desenvolvimento Social (IDS), formulado inicialmente em 1991, leva em consideração não a renda per capita, mas como esta é distribuída na sociedade através do coeficiente de Gini. Observa-se que o coeficiente de Gini é graduado de 0 a 1 , porém 0 (zero) representa a melhor situação para concentração de renda (distribuição completamente igualitária) enquanto 1 (hum) para a maior concentração de renda possível. Para compensar esta diferença adapta-se o coeficiente de Gini para a unidade menos o coeficiente dado pela base de dados. Assim, zero representaria a pior situação (completa concentração) e 1 (hum) a distribuição de renda mais

\footnotetext{
97 Instituto de Pesquisa Econômica Aplicada (IPEA); Fundação João Pinheiro (FJP) e Instituto Brasileiro de Geografia e Estatística (IBGE).
} 
igualitária. O IDS é calculado a partir da média aritmética simples das componentes concentração de renda, longevidade e educação, conforme descrito por Oliveira (2010);

3. Índice de Desenvolvimento Humano Municipal Ampliado (IDH-MA) - Por fim, o índice anteriormente apresentado leva em consideração a concentração da renda, porém não analisa a paridade do poder de compra. Tendo em vista este problema utilizaremos o Índice de Desenvolvimento Humano Municipal Ampliado (IDH-MA) que busca suprir esta necessidade. Para tal cálculo se leva em conta a média simples com quatro componentes, duas delas referentes à renda. Assim, o IDH-MA é calculado a partir dos indicadores de renda (renda per capita e coeficiente de Gini), indicador de educação e indicador de longevidade. (OLIVEIRA, 2010)

\section{METODOLOGIA SHIFT-SHARE}

A metodologia Shift-share (também chamada de Estrutural-Diferencial) é amplamente utilizada como ferramenta de sintetização de dados estatísticos através da análise dos componentes de variação de um indicador e é largamente utilizada para análise regional, tanto por economistas quanto por geógrafos. De acordo com Simões (2005, p.10), o método "consiste, basicamente, na descrição do crescimento econômico de uma região nos termos de sua estrutura produtiva".

Conforme Vale e Vasconcelos ${ }^{98}$ (1984 apud OLIVEIRA, 2010, p.120) devese criar um roteiro para a utilização da metodologia ${ }^{99}$. Este roteiro inclui: 1) escolha de uma região de análise a qual observar-se-á o desempenho dos municípios que a formam; 2) escolher as variáveis para análise e 3) "deve-se isolar os efeitos da variável para analisar o desempenho da estrutura no desenvolvimento regional". Portanto, a MFI é a região (universo) a ser analisada e os índices escolhidos, como já apresentados, são o IDH-M, IDS e IDH-MA.

\footnotetext{
${ }^{98}$ VALE e VASCONCELOS, A. Economia urbana. Porto/Portugal: Rés-editora, 1984.

99 "The classical shift-share equation is designed to decompose the growth of a regional variable such as employment, income or output into three effects that measure differential growth among regions" (Herzog e Olsen, 1977, p. 441)
} 
De acordo com Oliveira (2010), algebricamente, o modelo básico pode ser escrito da seguinte forma:

$$
\sum \Delta \mathrm{X}_{\mathrm{ik}}=\sum\left[\mathrm{X}_{\mathrm{ik}(\mathrm{t})}-\mathrm{X}_{\mathrm{ik}(\mathrm{t}-1)}\right]=\sum\left[\mathrm{N} \mathrm{X}_{\mathrm{ik}}+\mathrm{S} \mathrm{X}_{\mathrm{ik}}+\mathrm{R} \mathrm{X}_{\mathrm{ik}}\right] ;
$$

sendo que:

- $\Delta \mathrm{X}_{\mathrm{ik}}$ representa a variação observada na variável $\mathrm{X}_{\mathrm{ik}}$;

- $X_{\mathrm{ik} \text { (t) }}$ representa a variável econômica escolhida como explicativa $X$, medida na região $\mathrm{i}$, no setor $\mathrm{k}$, no período de análise $\mathrm{t}$, no caso a ser estudado, foram escolhidos os componentes do IDH-M, IDS e IDH-MA;

- $N X_{\text {ik }}$ representa o componente nacional, nessa averiguação esse componente refere-se ao agregado da Microrregião de Foz do Iguaçu (MFI);

- $\mathrm{SX}_{\mathrm{ik}}$ representa o componente estrutural de cada localidade (cidade) da MFI e;

- $\mathrm{RX}_{\mathrm{ik}}$ representa o componente regional, no caso, o componente de cada município que faz parte da MFI;

Para se obter as variáveis explicativas definidas anteriormente deve-se proceder da seguinte maneira:

$$
\begin{aligned}
& N X_{i k}=g_{N X} \cdot X_{i k(t-1)} ; \\
& S X_{i k}=\left(g_{N X K}-g_{N x}\right) \cdot X_{i k(t-1)} ; \\
& R X_{i k}=\left(g_{i k}-g_{N X K}\right) \cdot X_{i k(t-1)} ; \\
& \text { sendo que: }
\end{aligned}
$$

- $g_{N X}$ reflete a variação percentual da variável X observada a nível nacional (regional), no nosso caso a nível da MFI relativamente ao ano base $\mathrm{t}-1$;

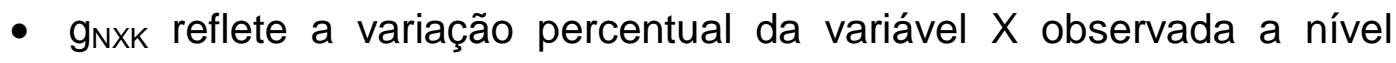
nacional (da MFI), referente ao setor $\mathrm{k}$ (cada um dos indicadores básicos do IDH-M, IDS e IDH-MA da amostra da região em estudo);

- $g_{i k}$ reflete a variação percentual da variável $X$, observada na região $\mathrm{i}$, no caso em cada município membro da MFI, no setor k (assim como o anterior, trata-se de cada um dos indicadores básicos do IDH-M, IDS e IDH-MA da MFI). 
Para facilitar a comparação desse trabalho com outros com a mesma metodologia, serão usadas e mantidas nos quadros de decomposição do crescimento em componentes de variação, a notação e interpretação apresentadas por Haddad e Andrade (1989). Para esses autores, a análise shift-share permite a identificação da variação do indicador selecionado através da VLT - Variação Líquida Total, que é o crescimento observado menos o teórico, ou seja, o crescimento que seria obtido caso as cidades mantivessem as mesmas taxas de crescimento da MFI, é o mesmo indicador de foi denominado de $N X_{i k}$. O VLT ou $\mathrm{NX}_{\mathrm{ik}}$ é obtido da seguinte forma: VLT $=\mathrm{VLE}+\mathrm{VLD}$. Sendo que: VLE, retrata a Variação Líquida Estrutural, no caso, é o mesmo que a componente estrutural ( $S X_{i k}$ ) e; VLD, reflete a Variação Líquida Diferencial ou componente diferencial, que aparece anteriormente como componente regional $\left(R X_{i k}\right)$, cujos resultados apontam que na localidade estudada (cada município da MFI) a variável tem um desempenho superior ou inferior ao das suas congêneres.

Agora, para compreensão plena dos resultados deve-se explicar dois conceitos importantes para a aplicação da metodologia e leitura dos gráficos sintetizadores. Tais conceitos são ativação social e eficiência alocativa. O primeiro, ativação social, se refere a variação regional (VLD) e o segundo, eficiência alocativa, dado pela variação estrutural (VLE). A ativação social reflete a capacidade de "transformar crescimento em desenvolvimento (capacidade de ativação social) 100" desde que a VLD seja positiva. O inverso é válido. Eficiência alocativa se refere a eficiência dos gastos públicos para alocação de recursos para melhoria nas áreas utilizadas em cada indicador. Para VLE $>0$ se verifica eficiência quanto a alocações desses recursos e $\mathrm{VLE}<0$ a ineficiência. Os possíveis resultados são resumidos por Oliveira (2010) no quadro 1. 
Quadro 01: Guia de interpretação dos resultados dispostos nos gráficos de decomposição do crescimento por índice escolhido e por município da MFI.

\begin{tabular}{|c|c|c|c|c|c|c|}
\hline \multirow{2}{*}{ Quadrante } & \multirow{2}{*}{$\begin{array}{l}\text { Eficiência } \\
\text { alocativa }\end{array}$} & \multirow{2}{*}{$\begin{array}{l}\text { Ativação } \\
\text { Social }\end{array}$} & \multirow{2}{*}{ VLT } & \multicolumn{2}{|c|}{ Componentes } & \multirow{2}{*}{ Interpretação } \\
\hline & & & & VLE & VLD & \\
\hline I & Presente & Presente & + & + & + & $\begin{array}{l}\text { Municípios com as maiores variações positivas dos indicadores } \\
\text { básicos componentes de cada índice estudado. }\end{array}$ \\
\hline \multirow{2}{*}{ \| } & Ausente & Presente & + & - & + & $\begin{array}{l}\text { A capacidade de ativação social }(V L D>0) \text { consegue suplantar a } \\
\text { ineficiência alocativa municipal }(V L E<0) \text { e ter um crescimento maior } \\
\text { que a média da MFI }(V L T>0) \text {. }\end{array}$ \\
\hline & Ausente & Presente & - & - & + & $\begin{array}{l}\text { Crescimento total abaixo da média regional (VLT negativo). } \\
\text { Possuem ativação social, porém, não conseguem superar a } \\
\text { ineficiência alocativa }(\mathrm{VLE}<0) \text {. }\end{array}$ \\
\hline III & Ausente & Ausente & - & - & - & $\begin{array}{l}\text { São municípios com baixas taxas de crescimento e baixa } \\
\text { participação no crescimento dos índices da região analisada, cuja } \\
\text { falta de ativação social é piorada pela ineficiência alocativa } \\
\text { municipal. }\end{array}$ \\
\hline \multirow{2}{*}{ IV } & Presente & Ausente & - & + & - & $\begin{array}{l}\text { Cidades com desempenho regular. A gestão municipal não } \\
\text { consegue evitar perdas líquidas, mas consegue manter a cidade } \\
\text { afastada da área de pior desempenho. }\end{array}$ \\
\hline & Presente & Ausente & + & + & - & $\begin{array}{l}\text { Embora com crescimento total acima da média regional (VLT>0), a } \\
\text { VLD<0 mostra que o município tem pouca capacidade de ativação } \\
\text { social. }\end{array}$ \\
\hline
\end{tabular}

Fonte: Oliveira (2010), modificado.

\section{ANÁLISE DOS DADOS}

A partir do software do PNUD (2003), foi extraída toda a base de dados e aplicada à metodologia. Estes dados produziram um conjunto de tabelas, que por fim puderam ser sintetizadas em gráficos para melhor análise. Nota-se que as variações percentuais relativas para os indicadores longevidade e educação são as mesmas para os três índices analisados, assim como as variações percentuais relativas à renda per capita para o IDH-M e o IDH-MA e a variação da concentração de renda para o IDS e o IDH-MA. As diferenças estão relacionadas às metodologias de cálculo utilizadas para cada índice, pois utilizam combinações de indicadores básicos distintas. 


\subsection{ANÁLISE DO IDH-M}

O IDH-M para a MFI passou de 0,7 em 1991 para 0,77 em 2000, caracterizando variação positiva de $10,43 \%$ sendo a componente educação a principal responsável pela evolução do desempenho do índice $(13,24 \%)$, seguida da componente longevidade $(9,32 \%)$ e a componente renda per capita $(8,19 \%)$. O município que melhor apresentou crescimento do IDM-M foi Céu Azul (16,29\%) e em contra partida Medianeira (6,66\%) apresentou o menor crescimento entre os municípios da microrregião.

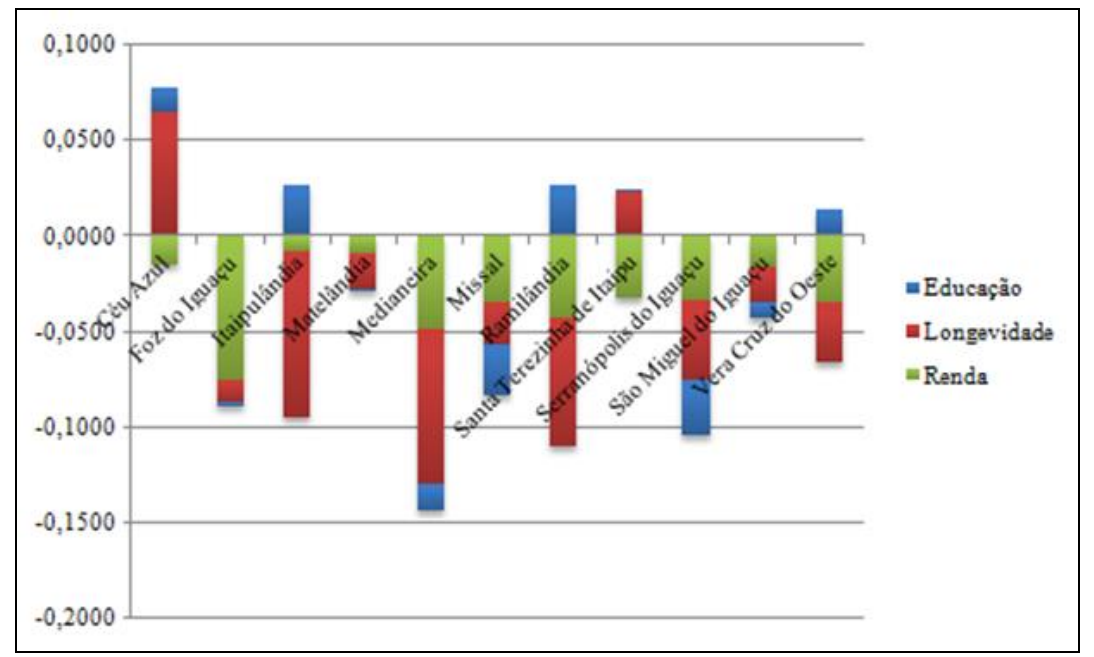

Gráfico 1: Componente regional por indicador básico do IDH-M: 1991-2000 Fonte: Elaboração própria

Fazendo uso dos dados obtidos e dos conceitos dispostos no quadro 2, pode-se observar que Céu Azul foi o único município da MFI que aparece localizado no primeiro quadrante do gráfico 02 . Tal posição indica que este município obteve as maiores variações dos indicadores básicos para o IDH-M. Por outro lado, Foz do Iguaçu, Itaipulândia, Ramilândia e Vera Cruz do Oeste apresentam variações abaixo da média regional. Nenhum município se encontra no terceiro quadrante. Já os municípios de Matelândia, Missal, Santa Terezinha de Itaipu, São Miguel do Iguaçu e Serranópolis do Iguaçu apresentam resultados abaixo da média regional (MFI). 


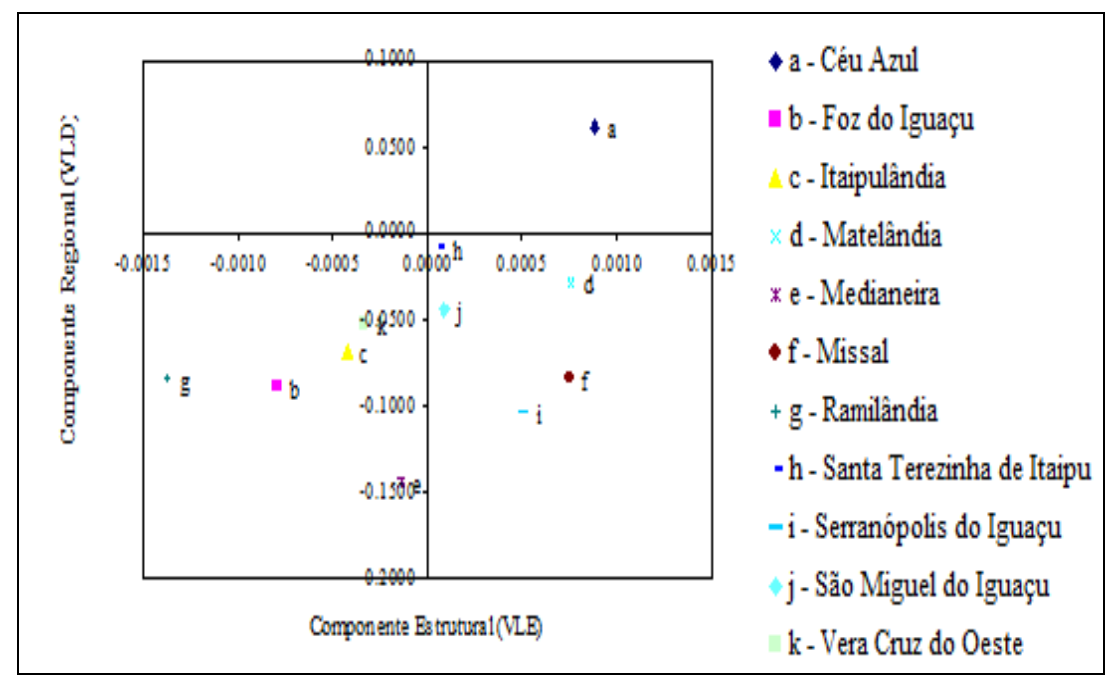

Gráfico 2: Representação da decomposição de crescimento do IDH-M: 1991-2000 Fonte: Elaboração própria

\subsection{ANÁLISE DO IDS}

O IDS apresentou variação de $8,47 \%$, ou seja, variação positiva, porém menor que o índice anteriormente analisado. Tal diferença se dá pela substituição do indicador renda per capita pelo de concentração de renda. O IDS passou de 0,63 a 0,68 no período. $O$ indicador concentração de renda apresenta oscilação negativa ($1,24 \%)$ para a região, enquanto os indicadores de educação $(13,24 \%)$ e longevidade $(9,32 \%)$ apresentaram oscilações positivas. Assim como o IDH-M, Céu Azul apresentou o maior crescimento do índice IDS com variação de 14,19\%. Em contra partida, Itaipulândia apresentou o menor crescimento com 2,23\%. O baixo crescimento deste índice para Itaipulândia se deve ao acentuado aumento da concentração de renda (17,65\%). Mesmo com este desempenho ruim, o município que apresentou maior disparidade na concentração de renda foi São Miguel do Iguaçu (-22,73\%). Enquanto isso, do total, cinco municípios apresentaram variação nula para a concentração da renda, três variação positiva e três variação negativa. Ademais, todos os municípios apresentaram variações positivas dos indicadores educação e longevidade. O gráfico 03 apresenta os resultados da componente regional de acordo com a metodologia. 


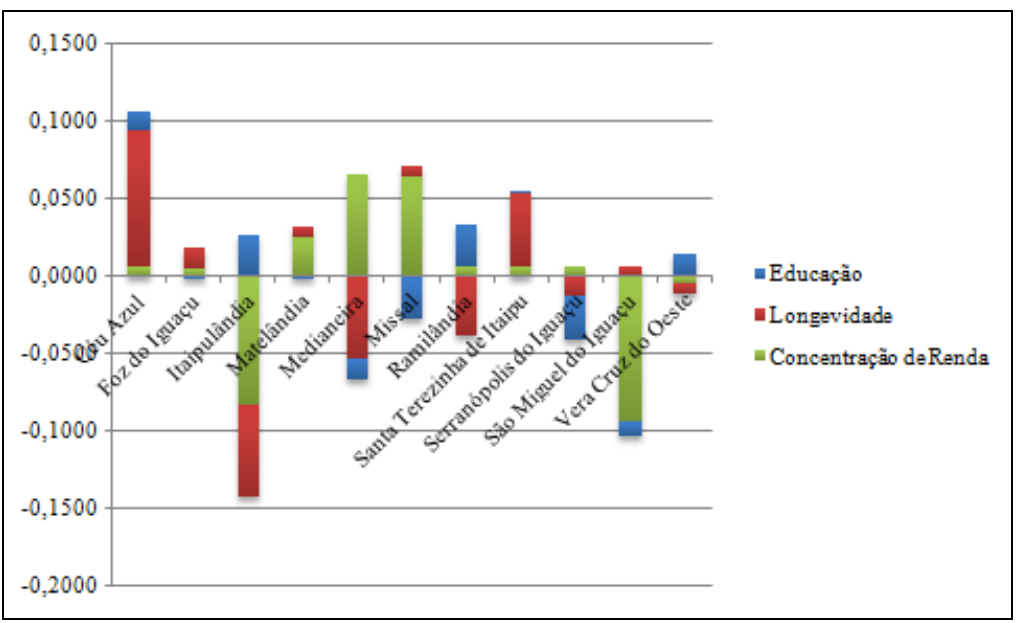

Gráfico 3: Componente regional por indicador básico do IDS: 1991-2000 Fonte: Elaboração própria.

Os municípios de Itaipulândia, Ramilândia, Serranópolis do Iguaçu e São Miguel do Iguaçu apresentaram variações negativas para a componente regional, o que representa que tiveram variação média menor que a taxa de crescimento do IDS na MFI. Para o gráfico 04, sintetizador das componentes estrutural e regional, temos no primeiro quadrante os municípios de Foz do Iguaçu, Medianeira, Missal e Vera Cruz do Oeste, ou seja, os municípios que apresentaram maiores variações nas componentes do IDS comparados à região. Por outro lado, os municípios que apresentaram maiores variações negativas foram Itaipulândia e Ramilândia, ambas situadas no terceiro quadrante, apresentando variações negativas para as duas componentes. Os demais municípios (Céu Azul Matelândia e Santa Terezinha de Itaipu) apresentaram variação acima da média regional, porém com variação negativa da componente estrutural ( $2^{\circ}$ quadrante), e, por outro lado, apresentando resultados abaixo da média regional e componente regional negativa se encontram os municípios de Serranópolis do Iguaçu e São Miguel do Iguaçu (4ำ quadrante). 


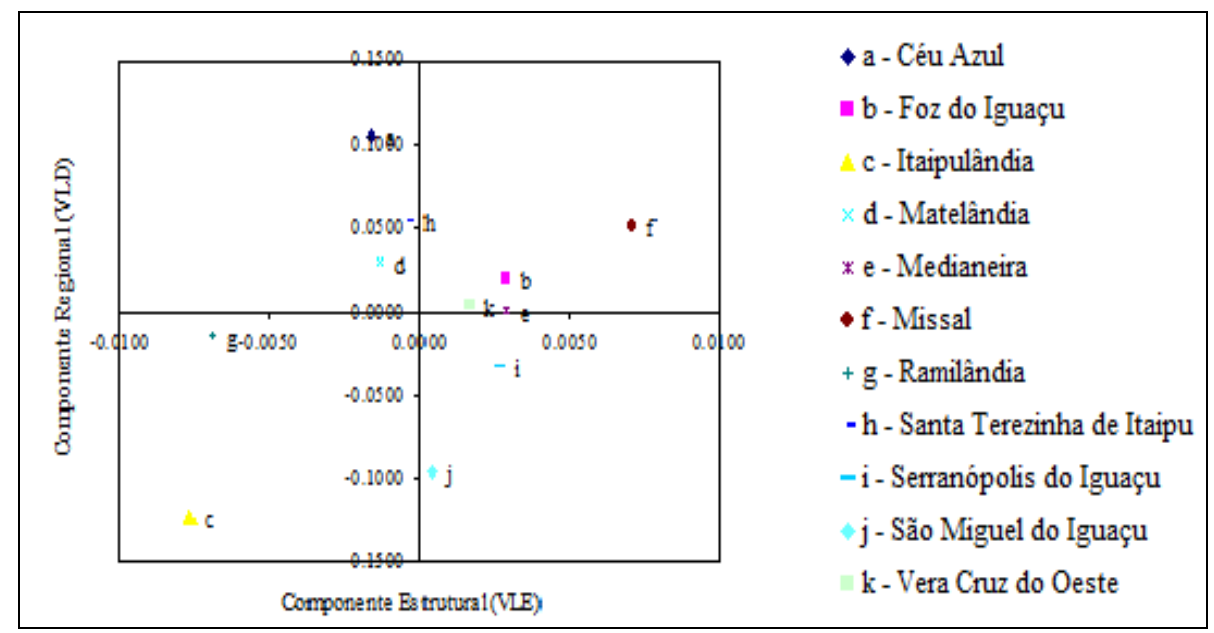

Gráfico 04: Representação da decomposição de crescimento do IDS: 1991-2000 Fonte: Elaboração própria.

\subsection{ANÁLISE DO IDM-MA}

No período de 1991 à 2000 houve variação de 8,4\% do índice IDHM-MA para a microrregião, puxado principalmente pelas variações dos indicadores educação $(13,24 \%)$, longevidade $(9,32 \%)$ e renda $(8,19 \%)$. Como já vimos para o IDS, a indicador de concentração de renda apresentou variação negativa $(-1,24 \%)$ para o período. Assim como os demais índices, Céu Azul apresentou o maior crescimento do IDH-MA (13,32\%) e Itaipulândia (4,49\%) a menor variação positiva. De modo geral, a microrregião apresentou em 1991 o IDH-MA igual a 0,63 passando a 0,68 em 2000 , crescimento de $7,93 \%$.

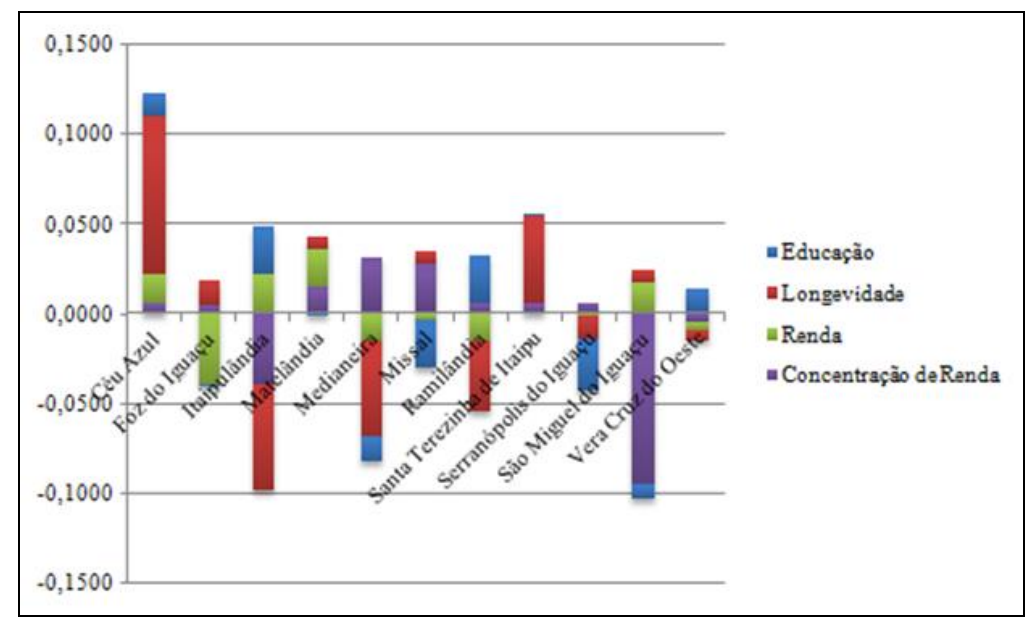

Gráfico 5: Componente regional por indicador básico do IDH-MA: 1991-2000 Fonte: Elaboração própria. 
A análise das componentes estrutural e diferencial para o IDH-MA estão sintetizados no gráfico 06. Os municípios que apresentaram maiores variações positivas para os indicadores do IDH-MA foram Matelândia e Missal, apresentando ambas variações positivas para as componentes apresentando eficiência alocativa e ativação social. Por outro lado, cinco dos municípios da microrregião apresentaram ambas componentes negativas, e por consequência variação líquida total negativas, o que as colocam no terceiro quadrante explicitando municípios que tiveram pior sucesso para aumentar a qualidade de vida de sua população. Tais municípios são: Foz do Iguaçu, Itaipulândia, Medianeira, Ramilândia e São Miguel do Iguaçu. Por fim, os municípios de Céu Azul, Santa Terezinha do Itaipu e Vera Cruz do Oeste se localizam no segundo quadrante e Serranópolis do Iguaçu no quarto quadrante.

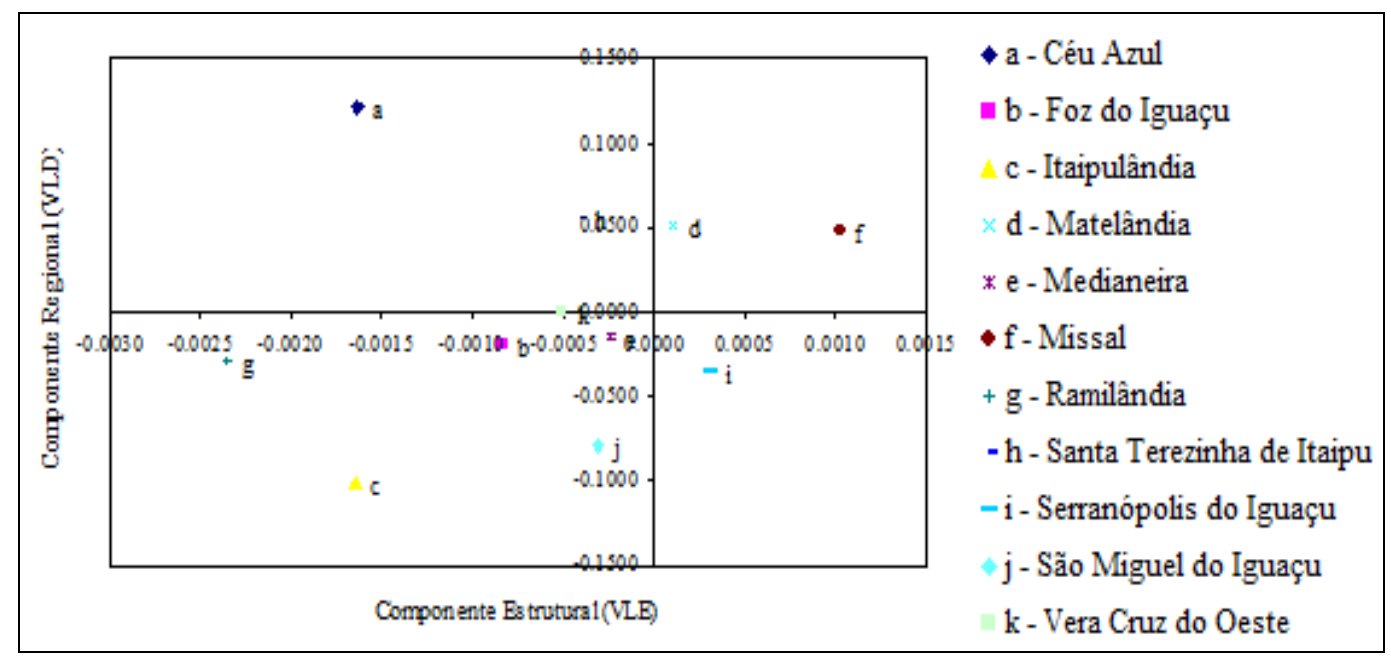

Gráfico 06: Representação da decomposição de crescimento do IDH-MA: 1991-2000 Fonte: Elaboração própria.

\section{CONSIDERAÇÕES FINAIS}

Os indicadores de desenvolvimento para a MFI apresentaram crescimento, assim como para cada município analisado individualmente. $O$ objetivo foi analisar como cada município colaborou, para mais ou para menos, com o desenvolvimento da região como todo. 
O estudo demonstrou que a aplicação da metodologia é de grande utilidade para a detecção de indicadores de desenvolvimento humano e social que desempenham melhor papel para o avanço do desenvolvimento em cada município comparando-o com a região, além de identificar em cada caso onde há problemas de eficiência alocativa, assim como ativação social cujo a presença pode auxiliar na melhoria da qualidade de vida.

Os resultados da decomposição com uso do shift-share, tanto do IDH-M, IDS e IDH-MA quanto dos seus indicadores básicos, podem nortear as políticas públicas municipais, estaduais e federais na tentativa de melhorar o desenvolvimento humano e social na MFI.

\section{REFERÊNCIAS}

ALVES, L. R. Urbanização e polarização das microrregiões paranaenses 1970/2000. 2005. Monografia (Bacharelado em Ciências Econômicas) Universidade Estadual do Oeste do Paraná - Campus de Toledo. Toledo, 2005.

AZZONI, C. R. Sobre a Necessidade da Política Regional. In: KON, A. (Org.). Unidade e Fragmentação: A Questão Regional no Brasil. Unidade e Fragmentação: A Questão Regional no Brasil. São Paulo: Editora Perspectiva, 2002.

HADDAD, P. R; ANDRADE, T. A. Método de análise estrutural-diferencial. In: HADDAD, P. R. (org.). Economia Regional: teorias e métodos de analise. Fortaleza: BNB/ETENE, 1989.

HERZOG, H. W; OLSEN, R. J. Shift-Share analysis revisited: the allocation effect and the stability of regional structure. Journal or Regional Science. 17 (3): 441-54, 1977.

IBGE. Divisão do Brasil em Mesorregiões e Microrregiões Geográficas. v. 1. Rio de Janeiro, 1990.

Instituto Brasileiro de Geografia e Estatística. Página eletrônica: www.ibge.gov.br. Acesso em: 01 nov. 2012.

Banco de dados agregados - SIDRA. Disponível em:

<http://www.sidra.ibge.gov.br/bda/>. 2005. Acesso em: 01 nov. 2012. 
LIMA, J. F. Dispersão e alocação do emprego nas atividades produtivas das microrregiões paranaenses. Toledo: Programa de Pós-Graduação em Desenvolvimento Regional e Agronegócios da UNIOESTE, 2007.

MUNIZ FILHO, C. Divisão regional do Paraná. Rev. parana. desenvolv., Curitiba, n.87. jan/abr.; 1996.

OLIVEIRA, G. B. O desenvolvimento na Região Metropolitana de Curitiba. 312 p. Tese (Doutorado em Desenvolvimento Econômico). Universidade Federal do Paraná. Curitiba: PPGDE/UFPR, 2010.

Uma Discussão sobre o Conceito de Desenvolvimento. Rev. FAE, Curitiba, v.5, n.2, p.45-48, maio/ago. 2002

PNUD. Programa das Nações Unidas para o desenvolvimento. Página eletrônica < http://www.pnud.org.br>. Acesso em: 01 nov. 2012.

Atlas do Desenvolvimento Humano no Brasil (2003). Software disponível em http://www.pnud.org.br. Acesso em: 01 nov. 2012.

PIERUCCINI, M.A; TSCHÁ, O. C; IWAKE, S. Criação dos Municípios e Processos Emancipatórios. In: PERIS, A. F. (org). Estratégias de Desenvolvimento Regional: Região Oeste do Paraná.Cascavel: Edunioeste, 2008.

RAIHER, A. P. A evolução do capital humano e sua importância no crescimento econômico das microrregiões paranaenses no período de 1999 a 2006. 141 p. Tese (Doutorado em Economia) - Universidade Federal do Rio Grande do Sul, Faculdade de Ciências Econômicas, Programa de Pós-graduação em Economia, Porto Alegre, 2009.

ROLIM, C. F. C. Como analisar as Regiões Transfronteiriças?: esboço de um enquadramento teórico-metodológico a partir do caso de Foz do Iguaçu. In: III Encontro Paranaense de Economia, 2004, Londrina. Anais do III Encontro Paranaense de Economia, 2004.

SANDRONI, P. Novíssimo Dicionário de Economia. São Paulo, Círculo do Livro; Best Seller, 1999.

SILVA, J. C. A análise de componentes de variação (shift-share). In: COSTA, J. S. (org). Compedio de economia regional. Coimbra/Portugal: APDR, 2002.

SIMÕES, R. F. Métodos de análise regional e urbana: diagnóstico aplicado ao planejamento. Belo Horizonte: Cedeplar/UFMG, 2005. 
Revista Tecnologia e Sociedade - 2ª Edição, 2013.

ISSN (versão online): 1984-3526

ISSN (versão impressa): 1809-0044

\section{ANEXO ESTATÍSTICO}

\begin{tabular}{|c|c|c|c|c|c|c|c|c|c|c|c|c|}
\hline \multirow{3}{*}{ Cidades } & \multicolumn{12}{|c|}{ Resultados do Shift - Share } \\
\hline & \multicolumn{3}{|c|}{ Indicador de Educação } & \multicolumn{3}{|c|}{ Indicador de Longevidade } & \multicolumn{3}{|c|}{ Indicador de Renda } & \multicolumn{3}{|c|}{ IDH-M } \\
\hline & VLT & VLE & VLD & VLT & VLE & VLD & VLT & VLE & VLD & VLT & VLE & VLD \\
\hline Cou Arul & 0,0342 & 0,0218 & 0,0124 & 0,0579 & $-0,0068$ & 0,0546 & $-0,0296$ & $-0,0141$ & $-0,0155$ & 0,0624 & 0,0009 & 0,0615 \\
\hline Foa do Igasçu & 0,0204 & 0,0225 & $-0,0020$ & $-0,0189$ & $-0,0072$ & $-0,0117$ & $-0,0913$ & $-0,0161$ & $-0,0752$ & $-0,0897$ & $-0,0008$ & $-0,0889$ \\
\hline Itripulsodia & 0,0476 & 0,0211 & 0,0264 & $-0,0943$ & $-0,0079$ & $-0,0854$ & $-0,0221$ & $-0,0136$ & $-0,0085$ & $-0,0689$ & $-0,0004$ & $-0,0684$ \\
\hline Matolisndia & 0,0214 & 0,0217 & $-0,0003$ & $-0,0269$ & $-0,0073$ & $-0,0196$ & $-0,0226$ & $-0,0137$ & $-0,0089$ & $-0,0280$ & 0,0008 & $-0,0288$ \\
\hline Modinain & 0,0084 & 0,0228 & $-0,0144$ & $-0,0885$ & $-0,0079$ & $-0,0007$ & $-0,0640$ & $-0,0150$ & $-0,0490$ & $-0,1442$ & $-0,0001$ & $-0,1441$ \\
\hline Minal & $-0,0042$ & 0,0229 & $-0,0272$ & $-0,0293$ & $-0,0079$ & $-0,0214$ & $-0,0496$ & $-0,0142$ & $-0,0353$ & \begin{tabular}{|l|}
$-0,0831$ \\
\end{tabular} & 0,0008 & $-0,0839$ \\
\hline Ramilsndia & 0,0455 & 0,0187 & 0,0268 & $-0,0749$ & $-0,0079$ & $-0,0670$ & $-0,0552$ & $-0,0122$ & $-0,0430$ & $-0,0846$ & $-0,0014$ & $-0,0832$ \\
\hline Sunta Terovinha do Inipa & 0,0232 & 0,0218 & 0,0014 & 0,0157 & $-0,0072$ & 0,0229 & $-0,0466$ & $-0,0145$ & $-0,0321$ & $-0,0077$ & 0,0001 & $-0,0078$ \\
\hline Serramopolis do Iguaça & $-0,0057$ & 0,0231 & $-0,0288$ & $-0,0496$ & $-0,0082$ & $-0,0414$ & $-0,0485$ & $-0,0144$ & $-0,0341$ & $-0,1039$ & 0,0005 & $-0,1044$ \\
\hline S3o Migaal do Igusçu & 0,0138 & 0,0221 & $-0,0083$ & $-0,0263$ & $-0,0073$ & $-0,0190$ & $-0,0308$ & $-0,0147$ & $-0,0161$ & $-0,0433$ & 0,0001 & $-0,0434$ \\
\hline Vera Crux do Oosto & 0,0345 & 0,0206 & 0,0140 & $-0,0396$ & $-0,0073$ & $-0,0322$ & $-0,0479$ & $-0,0136$ & $-0,0344$ & $-0,0530$ & $-0,0003$ & $-0,0526$ \\
\hline
\end{tabular}

Fonte: elaboração própria.

\begin{tabular}{|c|c|c|c|c|c|c|c|c|c|c|c|c|}
\hline \multicolumn{13}{|c|}{ Quadro 03 - Decomposição do crescimento em componentes em variação (IDS): 1991 e 2000} \\
\hline \multirow{3}{*}{ Cidades } & \multicolumn{12}{|c|}{ Resultados do Shift - Share } \\
\hline & \multicolumn{3}{|c|}{ Indicador de Educação } & \multicolumn{3}{|c|}{ Ind. de Longevidade } & \multicolumn{3}{|c|}{ Ind de Conc de Renda } & \multicolumn{3}{|c|}{ IDS } \\
\hline & VLT & VLE & VLD & VLT & VLE & VLD & VLT & VLE & VLD & VLT & VLE & VLD \\
\hline Céu Azul & 0,0494 & 0,0370 & 0.0124 & 0,0936 & 0,0052 & 0,0884 & $-0,0381$ & $-0,0437$ & 0.0056 & 0,1032 & $-0,0016$ & 0,1048 \\
\hline Foz do Iguaçu & 0,0362 & 0,0382 & $-0,0020$ & 0,0192 & 0,0055 & 0,0137 & $-0,0356$ & $-0,0408$ & 0.0052 & 0,0227 & 0,0029 & 0,0198 \\
\hline Itaipulândia & 0,0623 & 0,0359 & 0,0264 & $-0,0524$ & 0,0061 & $-0,0584$ & $-0,1332$ & $-0,0495$ & $-0,0837$ & $-0,1309$ & $-0,0076$ & $-0,1233$ \\
\hline Matelândia & 0.0365 & 0,0369 & $-0,0003$ & 0,0116 & 0,0056 & 0,0061 & $-0,0181$ & $-0,0437$ & 0.0256 & 0,0287 & $-0,0013$ & 0,0300 \\
\hline Medianeira & 0,0243 & 0,0387 & $-0,0144$ & $-0,0470$ & 0,0060 & $-0,0530$ & 0,0236 & $-0,0418$ & 0,0653 & 0,0038 & 0,0029 & 0,0009 \\
\hline Missal & 0,0118 & 0,0390 & $-0,0272$ & 0.0126 & 0,0061 & 0,0066 & 0,0270 & $-0,0379$ & 0.0648 & 0,0585 & 0,0071 & 0.0514 \\
\hline Ramiländia & 0,0586 & 0,0318 & 0,0268 & $-0,0331$ & 0,0060 & $-0,0392$ & $-0,0390$ & $-0,0447$ & 0,0057 & $-0,0204$ & $-0,0069$ & -0.0135 \\
\hline $\begin{array}{l}\text { Santa Terezinha } \\
\text { de Itaipu } \\
\end{array}$ & 0,0384 & 0,0370 & 0.0014 & 0,0535 & 0,0055 & 0,0481 & $-0,0373$ & $-0,0427$ & 0.0055 & 0,0543 & $-0,0003$ & 0,0546 \\
\hline $\begin{array}{l}\text { Serranópolis do } \\
\text { Iguaçu }\end{array}$ & 0,0104 & 0,0392 & $-0,0288$ & $-0,0063$ & 0,0062 & $-0,0126$ & $-0,0373$ & $-0,0427$ & 0.0055 & $-0,0305$ & 0,0027 & $-0,0332$ \\
\hline $\begin{array}{l}\text { São Miguel do } \\
\text { Iguaçu }\end{array}$ & 0,0293 & 0,0376 & $-0,0083$ & 0,0123 & 0,0056 & 0,0068 & $-0,1373$ & $-0,0427$ & -0.0945 & $-0,0953$ & 0,0004 & -0.0957 \\
\hline $\begin{array}{l}\text { Vera Cruz do } \\
\text { Oeste }\end{array}$ & 0,0489 & 0,0350 & 0.0140 & $-0,0008$ & 0,0056 & $-0,0064$ & $-0,0439$ & $-0,0389$ & -0.0050 & 0,0059 & 0,0017 & 0.0042 \\
\hline
\end{tabular}

Fonte: elaboração própria. 
Revista Tecnologia e Sociedade - 2ª Edição, 2013.

ISSN (versão online): 1984-3526

ISSN (versão impressa): 1809-0044

\begin{tabular}{|c|c|c|c|c|c|c|c|c|c|c|c|c|c|c|c|}
\hline Quadro & mpo & do $c$ & imen & comy & ntes en & ação & I-MA) & le 20 & & & & & & & \\
\hline & & & & & & & Resulta & os do Shi & - Share & & & & & & \\
\hline Cidades & Indica & lor de Edu & acação & Ind. & le Longev & lade & Ind & ador de $\mathrm{R}$ & & Ind. de & Conc. de & Renda & & IDH-M & \\
\hline & VLT & VLE & VLD & VLT & VLE & VLD & VLT & VLE & VLD & VLT & VLE & VLD & VLT & VLE & VLD \\
\hline Céu Azul & 0,0499 & 0,0375 & 0,0124 & 0,0940 & 0,0056 & 0,0884 & 0,0150 & $-0,0013$ & 0,0163 & $-0,0378$ & $-0,0434$ & 0,0056 & 0,1194 & $-0,0016$ & 0,1211 \\
\hline $\begin{array}{l}\text { Foz do } \\
\text { Igruaçu }\end{array}$ & 0,0219 & 0,0239 & $-0,0020$ & 0,0080 & $-0,0057$ & 0,01 & $-0,0533$ & $-0,0144$ & $-0,0389$ & 0,0006 & $-0,0046$ & 0,0052 & $|-0,0202|$ & $-0,0008$ & $-0,0193$ \\
\hline Medianeira & 0,0099 & 0,0242 & $-0,0144$ & $-0,0593$ & $-0,0063$ & $-0,0530$ & $-0,0285$ & $-0,0135$ & $-0,0151$ & 0,0264 & $-0,0047$ & 0,0311 & $-0,0144$ & $-0,0002$ & $-0,0142$ \\
\hline \begin{tabular}{|l|} 
Missal \\
\end{tabular} & $-0,0028$ & 0,0244 & $-0,0272$ & 0,0002 & $-0,0063$ & 0,0066 & $-0,0160$ & $-0,0128$ & $-0,0032$ & 0,0240 & $-0,0043$ & 0,0282 & 0,0492 & 0,0010 & 0,0482 \\
\hline Ramilândia & 0,0467 & 0,0199 & 0,0268 & $-0,0455$ & $-0,0063$ & $-0,0392$ & $-0,0265$ & $-0,0109$ & $-0,0156$ & 0,0007 & $-0,0051$ & 0,0057 & \begin{tabular}{|l|}
$-0,0313$ \\
\end{tabular} & $-0,0024$ & $-0,0289$ \\
\hline \begin{tabular}{|l|} 
Santa \\
Terezinha de \\
Itaipu \\
\end{tabular} & 0,0245 & 0,0231 & 0,0014 & 0,0424 & $-0,0057$ & 0,0481 & $-0,0123$ & $-0,0130$ & 0,0007 & 0,0006 & $-0,0048$ & 0,0055 & 0,0549 & $-0,0004$ & 0,0553 \\
\hline \begin{tabular}{|l|} 
Vera Cruz do \\
Oeste \\
\end{tabular} & 0,0359 & 0,0219 & 0,0140 & $-0,0123$ & $-0,0058$ & $-0,0064$ & $-0,0159$ & $-0,0122$ & $-0,0037$ & $-0,0094$ & $-0,0044$ & $-0,0050$ & 0,0000 & $-0,0005$ & 0,0005 \\
\hline
\end{tabular}

Fonte: elaboração própria. 